\title{
Article
}

\section{Sustainable procurement strategies for competitive advantage: An empirical study}

Renukappa, Suresh Hennagara, Akintoye, Akintola, Egbu, Charles and Suresh, Subashini

Available at http://clok.uclan.ac.uk/19857/

Renukappa, Suresh Hennagara, Akintoye, Akintola ORCID: 0000-0002-06115824, Egbu, Charles and Suresh, Subashini (2016) Sustainable procurement strategies for competitive advantage: An empirical study. Proceedings of Institution of Civil Engineers: Management, Procurement and Law, 169 (1). pp. 17-25. ISSN 1751-4304

It is advisable to refer to the publisher's version if you intend to cite from the work. http://dx.doi.org/10.1680/jmapl.15.00006

For more information about UCLan's research in this area go to http://www.uclan.ac.uk/researchgroups/ and search for <name of research Group>.

For information about Research generally at UCLan please go to http://www.uclan.ac.uk/research/

All outputs in CLoK are protected by Intellectual Property Rights law, including Copyright law. Copyright, IPR and Moral Rights for the works on this site are retained by the individual authors and/or other copyright owners. Terms and conditions for use of this material are defined in the policies page.

\section{CLoK}

Central Lancashire online Knowledge www.clok.uclan.ac.uk

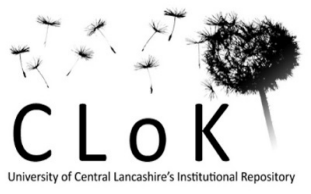


Management, Procurement and Law Volume 169 Issue MP1

Sustainable procurement strategies for competitive advantage: an empirical study Renukappa, Akintoye, Egbu and Suresh
Proceedings of the Institution of Civil Engineers

Management, Procurement and Law 169 February 2016 Issue MP1

Pages 17-25 http://dx.doi.org/10.1680/jmapl.15.00006

Paper 1500006

Received 09/03/2015 Accepted 18/08/2015

Published online 26/11/2015

Keywords: corporate responsibility/procurement/sustainability

\section{Sustainable procurement strategies for competitive advantage: an empirical study}

1 Suresh Renukappa DCE, BEng, MEng, PhD, PGCAPHE, MInLM, FHEA

Senior Lecturer, Faculty of Science and Engineering, University of Wolverhampton, Wolverhampton, UK

2 Akintola Akintoye BSc, MSc, PhD, FRICS, FCIOB Dean, Grenfell-Baines School of Architecture, Construction and Environment, University of Central Lancashire, Preston, UK
3 Charles Egbu BSC (Hons), PhD, FRICS, FCIOB, FAPM, FRSA, FHEA

Dean, School of the Built Environment and Architecture, London South Bank University, London, UK

4 Subashini Suresh BEng, MEng, PGCLTHE, PhD, FHEA Reader in Construction Project Management, Faculty of Science and Engineering, University of Wolverhampton, Wolverhampton, UK
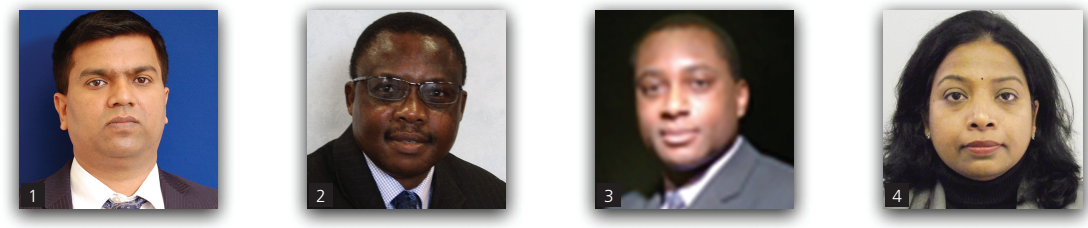

Procurement plays a key role in sustainability as policies and practices need to extend beyond organisations' boundaries to incorporate their whole supply chains. There is, however, a paucity of empirical research on sustainable forms of procurement initiatives currently being implemented in the UK construction sector to improve competitiveness - which is the core driver of this paper. In order to achieve this aim, a mixed research methodological approach was adopted to collect and analyse data. The findings are based primarily on quantitative data obtained from 53 completed postal questionnaires and semi-structured interviews with 17 professionals from 12 UK construction organisations. As revealed by this study, sustainable procurement is becoming increasingly important in the UK construction sector. The paper concludes that the process of integrating sustainable procurement initiatives into existing business models is often a complex issue. Therefore, there is an urgent need to explore the drivers and impediments associated with the successful integration of sustainable procurement initiatives into existing construction business models. It is also suggested that there is a need for cross-sector collaboration to capture and share best and worst practices relating to sustainable procurement strategies.

\section{Introduction}

The defining characteristic of the successful twenty-first-century organisation will be its ability to embed sustainability in every fibre of its operations. And, even more importantly, embedded sustainability will hold the key to future profit and value creation. Porter and Kramer (2011) noted that organisations continue to view value creation narrowly, optimising short-term financial performance in a bubble, while missing the most important customer needs and ignoring the broader influences that determine their longer-term success. For instance, the recent Accenture global survey revealed that $63 \%$ of CEOs expect sustainability to transform their industry within 5 years and $76 \%$ believe that embedding sustainability strategy into core business will drive revenue growth and new opportunities (Accenture, 2013). Furthermore, the KPMG (2013) survey revealed that $95 \%$ of the largest G250 organisations in the world are currently publishing sustainability reports and $82 \%$ of the G250 align with sustainability reporting standards developed by the Global Reporting Initiative. However, this is a small proportion of the approximately 58000 listed organisations worldwide, and most have not yet incorporated sustainability issues into their overall business strategy. But even as they make progress in embedding sustainability through their business, it is becoming increasingly apparent that organisations are constrained by market expectations and are struggling to quantify and capture the business value of sustainability.

van Kleef and Roome (2007) noted that a sustainable business management practice has to acknowledge the embeddedness in social, environmental and economic systems and focus on management and relationships to meet the environmental, social and economic requirements of many different stakeholders in its networks. Therefore, a more practical definition of sustainability principles focuses on the 'triple bottom line' and associated sustainability performance (Elkington, 2001). The triple bottom line approach therefore looks at how organisations manage and balance all three responsibilities (i.e. economic, environmental and social) and attempts to reconcile these inter-related spheres of activity for a more balanced view of overall business 
performance. However, consideration of social, economic and environmental factors by businesses is difficult as Hawkins (2006) states that it is a complex task to factor it into business decision making.

\subsection{Sustainable procurement}

In terms of striving for sustainable development, it is important to consider both an organisation's production and consumption patterns (Welford, 1997). In other words, a comprehensive account of an organisation's environmental impact requires attention to management of its supply chain. The development of 'environmental procurement' or 'green procurement' was seen as one part of a raft of initiatives to promote the general goal of sustainable development. According to the European Union (EU, 2011), 'environmental procurement' or 'green' procurement is defined as a process whereby authorities seek to procure goods, services and works with a reduced environmental impact throughout their life cycle when compared to goods, services and works with the same primary function that would otherwise be procured. Given that sustainable development has taken on an important social dimension, it is not surprising that there is now a growing interest in the social aspects of procurement. Barraket and Weissman (2009) noted that social procurement is the use of purchasing power to create social value. In the social procurement market, the purchaser wants delivery of a quality product, at a competitive price plus a social value. The supplier is responsible to provide both the business needs and a social value.

There has been growing debate about how aspects of social and environmental sustainability issues can be combined with financial factors to produce 'sustainable procurement' (McCrudden, 2004; Renukappa, 2009; Rwelamila et al., 2000; Varnäs et al., 2009). Sustainable procurement is defined as the process through which organisations buy assets, supplies and/or services, taking into account a number of issues, including traditional factors such as price, quality, availability, functionality; environmental sustainability aspects (i.e. the effect on the environment that the product has over the entire value chain); and social responsibility aspects (i.e. effects on issues such as ethical sourcing, human rights and employee conditions) (AccountAbility, 2004; Meehan and Bryde, 2011; UN Global Compact, 2013; UNDP, 2008). Therefore, sustainable procurement is all about taking social and environmental factors into consideration alongside financial factors in making purchasing decisions. It involves looking beyond the traditional economic parameters and making decisions based on the whole-life cost, the associated risks, measures of success and implications for society and the environment.

Sustainable procurement, according to McCrudden (2004), can assist in delivering government objectives like encouraging innovation in domestic supply markets, through the use of public money in supporting social and environmental aims. It is possible for organisations that engage in sustainable practices to achieve greater social, economic and environmental performances than organisations that simply focus on economic performance alone.
For instance, many large organisations in the world now account and report on the emissions from their direct operations. However, emissions along the value chain often represent a company's biggest greenhouse gas impact, which means that businesses need to act on the full range of the corporate value chain and product emissions as well. According to the Carbon Trust (2013), developing a full carbon dioxide emissions inventory would help businesses to identify and understand risks and opportunities associated with value chain emissions; identify carbon dioxide emissions reduction opportunities, set reduction targets and track performance; engage suppliers and other value chain partners in carbon dioxide management and sustainability; and enhance stakeholder information and corporate reputation through public reporting.

In order to respond to key stakeholders' demands and embrace sustainable procurement initiatives, organisations across sectors have implemented various change programmes to deal with sustainable procurement initiatives. However, it is widely asserted that a high proportion of change initiatives fail (Benn et al., 2014; Doppelt, 2009; Senge et al., 2007). As Beer and Nohria (2000) noted, most change initiatives do not work because they focus on only one key organisational factor rather than on the interdependencies among several key factors. Several change models also stress the importance of targeting technical, structural, social-cultural and human resources factors when developing programmes of planned change (Kotter, 1990).

Analysis of the above literature review reveals that sustainable procurement should not be considered in isolation (i.e. only economic or environmental or social aspects). Sustainable procurement requires a holistic view of the environmental, social and economic dimensions.

\subsection{Competitive advantage}

Competition is at the core of the success or failure of firms. Whether an organisation is doing well or not, competition is one of the main factors why. In other words, this determines the suitability of an organisation's activities, which can add to its performance (Porter, 1985). These include factors such as innovations, interconnected structure and thorough implementation. In addition, competitive strategy is the ideal competitive place in the industry for an organisation, and this ideal area is where competition happens. Fundamentally, competitive strategies intend to lay the foundations for a profitable and sustainable position when faced with industry competition (Porter, 1985). Indeed, Porter (1985) acknowledges that cost advantage and differentiation are the two types of competitive advantage that an organisation possesses.

A seminal empirical study by Fombrun and Shanley (1990) provides evidence that social responsiveness, as measured by the level of corporate charitable donations and the presence of a separately endowed corporate charitable foundation, is positively associated with corporate reputation. Williams and Barrett (2000) 
provide more evidence in support of a link between community engagement and firm reputation. In addition, they show that the link between community activities and reputation is stronger among companies that more frequently violate occupational health and safety and environmental regulations. They argue that, among other things, charitable giving can partially restore a firm's reputation after it has committed illegal acts (Williams and Barrett, 2000).

Some of the objectives for community engagement initiative(s) such as philanthropic activities are increased visibility, enhancing corporate reputation, and redressing negative publicity (Kotler and Lee, 2005). Thus, meeting strategic objectives can be an important, if not primary, goal of community engagement initiative(s). Executives see themselves in situations where there are increasing societal demands for social responsibility and investor pressure for short-term profits (Porter and Kramer, 2011). Because of these conflicting stakeholder interests, the ability to tie corporate giving to strategic objectives has grown in importance. Additionally, when philanthropic activity directly benefits all parties, including the sponsoring organisation, it is likely to be more sustainable and less likely to be one of the first things cut during downturns.

\section{The UK construction sector}

Many studies highlight that the construction industry plays a crucial role in the adoption of sustainable procurement practices (Kahlenborn et al., 2011; PricewaterhouseCoopers, 2009; Renda et al., 2012; Renukappa, 2009; Rwelamila et al., 2000; Varnäs et al., 2009). The construction industry is a significant part of the UK economy. The UK construction industry provides $10 \%$ of the UK's GDP and employees over 3 million people in over 250000 firms. Furthermore, the industry is key to the quality of life - in terms of housing, utilities and transport infrastructure (HM Government, 2009). In the UK almost $10 \%$ of the carbon dioxide emissions arise from the production and use of building materials. Also, the UK construction industry consumes over 1.2 million $\mathrm{t}$ of oil equivalent energy and produces over 3.62 million $t$ of carbon dioxide equivalent greenhouse gases. The construction industry produces over 78 million $\mathrm{t}$ of construction waste per annum, $17 \%$ of the UK total (HM Government, 2009). It is therefore crucial to improve the sustainability performance in this sector, where sustainable procurement can function as an important incentive.

Procurement plays a key role in sustainability as policies and practices need to extend beyond organisations' boundaries to incorporate their whole supply chains. However, there is a paucity of empirical research on how the UK construction sector is addressing sustainable procurement issues (environmental, social and economic) in their whole supply chain. Therefore, it is crucial to investigate the key sustainable procurement initiatives currently being implemented in the UK construction sector, so as to improve their competitiveness - which is the core aim of this paper.

\section{Research methodology}

It is important to have a robust research methodology to be able to achieve the aims and research objectives of the investigation. In this study, a sequential mixed research methodological approach was adopted to collect and analyse data in order to capture adequately the complexity of the research topic (Creswell, 2009). Mixed method design typically comprises both quantitative and qualitative methods in order to capture the holistic research needs, and includes a diversity of viewpoints and improved inference levels of granularity (Teddlie and Tashakkori, 2003). For example, quantitative methods often ensure that there is sufficient breadth of coverage, whereas qualitative methods can help facilitate a more in-depth examination of the study's key objectives. Thus, collected data not only broaden the scope of the study but also facilitate better inference and opportunities to detect divergences in the data.

In this study, standard sources of information such as trade and telephone directories, business information publications (i.e. Financial Analysis Made Easy and AP Information Limited database), and the Internet were used to identify the samples for the distribution of the postal questionnaire. In total, 414 samples were randomly selected. From the sample data set of 414, 53 fully completed and usable questionnaires were received, representing a $12 \cdot 8 \%$ response rate. The response rate is within the range Baruch and Holtom (2008) identified as appropriate for survey-based research related to sustainability. Survey respondents included board members, directors, advisers and managers responsible for corporate sustainability initiatives in their respective organisations. Descriptive analysis was used to analyse the quantitative data obtained from the 53 completed postal questionnaires. The quantitative results were further augmented by qualitative results generated through interviews.

Qualitative research, based on an interpretive paradigm, enables researchers to gain information about an area in which little is known (Liamputtong and Ezzy, 2005). Qualitative data were collected through semi-structured interviews. Semi-structured interviews provide some flexibility and are one of the ways to obtain a 'realistic' picture of an individual's view (Bryman and Bell, 2007). The purposive sampling technique was used in order to achieve representativeness (Teddlie and Tashakkori, 2003). To ensure greater dependability and transferability (Creswell, 2009), a total of 17 individual professionals from 12 UK construction organisations were interviewed. The interviews lasted between 30 and $90 \mathrm{~min}$. The format of these interviews was face-to-face, and the transcripts were recorded and supplemented with field notes as appropriate. The semi-structured interview sample included board members, directors, advisers and managers responsible for corporate environmental, social and economic sustainability initiatives in their respective organisations. Survey respondents and interviewees were from construction contractors and subcontractors of various sizes.

Analysis of the interviews was undertaken using content analysis, which is increasingly being used in qualitative studies (Silverman, 
2004). The use of content analysis enabled large amounts of textual information to be evaluated - for example, the frequencies of most used keywords in context and so on. Threats to validity were minimised through triangulation of data collection methods (interviews, internal and external documents) and verification of the initial thematic codes by participants, where they assessed the accuracy of data collected, though not its conclusions.

\section{Findings and discussion}

\subsection{Level of implementation of key sustainable procurement initiatives}

Through the postal survey questionnaire, respondents were asked to indicate the level of implementation of key sustainable procurement initiatives on a 4-point Likert scale ranging from 'Don't have any plan for implementation (1)', 'Planned to be implemented in the next 5 years (2)', 'Implemented but not in current use (3)' and 'Implemented and in use (4)'. Fellows and Liu (2014) noted that Likert scales are concerned with determining respondents' degrees of agreement or disagreement with a statement on, usually, a 5-point or 7-point scale. A general problem occurs in the application of opinions or attitude scales in questionnaire surveys: respondents tend towards the neutral position. Furthermore, the neutral response is often used to express the respondent's lack of opinion. The respondent may not have understood the question, the question may not be applicable or the respondent may not know the answer. In these cases, respondents will sometimes choose a safe neutral response rather than leaving the question unanswered. Therefore, in this study, a 4-point Likert scale is used in order to avoid the neutral response.

In this study, $53 \%$ (28 of 53) of the survey respondents indicated that their organisations had implemented sustainable procurement initiatives. This indicates that sustainable procurement is becoming increasingly important due to government investment whereby construction organisations need to operate as a ' $100 \%$ sustainable procurement organisation' in order to deliver wider objectives of sustainability to satisfy international and national directives.

\subsection{Key sustainable procurement strategies}

To validate the quantitative results and in order to further explore these data in depth, interviewees were asked through face-toface interviews to list and describe key sustainable procurement initiatives that have been implemented in their organisations through face-to-face interviews. Analysis of the qualitative data revealed that 11 of 17 interviewees noted that their organisations had implemented sustainable procurement initiatives such as purchasing construction-related materials from small/local organisations, reducing waste, health and safety (requiring health and safety measures and/or standards) of suppliers, workplace practices (all suppliers should strictly comply with laws, regulations and social standards), discrimination, working hours, employee compensation, ethical behaviour and rights of minorities, and helping suppliers in terms of gaining ISO 14001 certification (ISO, 2015).
Many of these interviewees noted that their organisations now recognised the importance of sustainable procurement strategies and the potential impact on long-term corporate profitability. Therefore, organisations are increasingly managing their suppliers' environmental and social performance to ensure that materials and equipment supplied by them are environmentally sustainable and socially responsible. However, many organisations did not claim to address environmental and social issues consistently in the supplier selection and evaluation criteria. Rather, conventional factors such as cost, quality and time were dominant factors in the assessment of their suppliers.

While the remaining 6 of 17 interviewees noted that their organisations were yet to develop a coherent sustainable procurement strategy, many of these interviewees noted that there were a number of significant obstacles preventing their organisations from practising sustainable procurement initiatives. The most often cited concerns include lack of demand from clients for sustainable procurement, lack of tools showing how to put sustainable procurement initiatives into practice, lack of commitment from suppliers for sustainability, not being aware of the economic advantages of sustainable procurement, lack of leadership from the supplier side and lack of demand for sustainability products (e.g. because of higher prices for sustainable resources/products). Overall, the qualitative results discussed above are in concordance with the 53 respondents who participated in the postal questionnaire survey of the study.

Analysis of the above qualitative results suggests that most often, implemented initiatives under the umbrella of sustainable procurement are diverse, but as shown in Table 1, four initiatives stand out.

From the data in Table 1, it is clear that integrating environmental and social criteria into supplier selection is the most implemented initiative. This is followed by monitoring supplier environmental and social performance, ethical trading, and collaborating with suppliers. Each of these initiatives is discussed below.

Sustainable procurement initiatives Number of interviewees cited $(N=11)$

$\begin{array}{lc}\begin{array}{l}\text { Integrating environmental and social } \\ \text { criteria into supplier selection }\end{array} & 6 \\ \text { process } & \\ \text { Monitoring supplier environmental } & 5 \\ \quad \text { and social performance } & 4 \\ \text { Ethical trading } & 2 \\ \text { Collaborating with suppliers } & \end{array}$

Table 1. Sustainable procurement initiatives that have been implemented in the UK construction sector 


\subsubsection{Integrating environmental and social criteria into the supplier selection process}

Koplin et al. (2007) state that the integration of environmental and social criteria into supply policies and processes forms a top priority for future corporate supply management. Of the 11 interviewees who noted that their organisations had implemented sustainable procurement initiatives, six stated that their organisations considered both environmental and social criteria when it comes to supplier selection; four out of 11 noted that their organisations considered only environmental criteria (e.g. natural resources consumption, carbon dioxide emissions, biodiversity, waste reduction strategies and water use) when selecting supplier or influencing present supplier over their environmental activities; and two out of eleven noted that their organisations considered only social criteria (e.g. community engagement activities, employee well-being strategies, charity activities and health and safety initiatives) when selecting their supplier. Analysis of these results suggests that integrating environmental and social criteria into the supplier selection process is widely implemented in the construction sector. For instance, one of the interviewees noted that their organisation had a green procurement programme. In this programme, suppliers were requested to identify their product and/or service that had the most environmental and social impact. The interviewee further noted that since their suppliers are from Europe, there is a high guarantee that the suppliers had met the social responsibility requirements according to expectations. The interviewee was certain that their suppliers do not engage in child labour, forced labour, or violation of human rights, because these practices are unacceptable in the European Union. However, another interviewee noted that their organisation had invested in a programme of third-party ethical audits of its suppliers. Since their suppliers are from developing and third-world countries, their organisation was willing to participate in tracking social issues in the suppliers' operations.

\subsubsection{Monitoring supplier environmental and social performance}

Of the interviewees, five out of 11 noted that their organisations monitored the environmental and social performance of their suppliers. Monitoring suppliers' environmental and social performance processes involves activities such as gathering and processing supplier information through publicly disclosed environmental and social records, company-specific questionnaires, and audits conducted by either the buyer or an independent third party (Min and Galle, 2001). Assessing and monitoring environmental (e.g. waste and carbon dioxide emissions performance) and social (e.g. human rights and ethical issues) performance help suppliers to undertake measures that ensure environmental quality and social responsibility of products and/or services.

\subsubsection{Ethical trading}

Of the interviewees, four out of 11 noted that their organisations had integrated ethical trading responsibilities into procurement standards (i.e. prohibiting personal relationships between suppliers and procurement agents, favouring suppliers). The results suggest that ethical trading initiatives are moderately implemented in the construction sector. Many interviewees perceive that social aspects of procurement are a good practice but not well internalised in their organisations, except for a few large organisations which have been very progressive in pushing social aspects of sustainability in the supply chain. Ethical trading responsibilities were achieved by identifying and training tradingrelated managers. The implementation of social practices often leads to increased process innovation, and innovative behaviour of employees creates greater organisational support (Porter and van der Linde, 1995; Yuan and Woodman, 2010). In contrast to an unfair work environment, balanced working hours and sufficient breaks should improve workers' attention to their tasks and reduce errors, which in turn may enhance the quality of supplier products and increase supply security.

\subsubsection{Collaborating with suppliers}

Firms foster sustainability in their supplier base in reaction to growing sustainability requirements in various ways, including sustainable supplier collaboration (Hollos et al., 2012). Handfield et al. (2001) noted that collaboration across internal departments and with suppliers is essential for maintaining robust sustainable procurement practices. For instance, in using sustainable procurement initiatives, an organisation must coordinate its product design department with its marketing department and its suppliers in an effort to minimise waste and environmental impact at every node in the supply chain. Of the interviewees, only two out of 11 noted that in general terms their organisations maintained close, supportive relationships with suppliers - usually local small and medium-sized suppliers. Analysis of the above result suggests that collaborating with suppliers for sharing sustainable procurement-related information and knowledge is very much less embraced in the construction sector. The most often cited collaborative support includes focusing on technical support, assistance for equipment acquisition, internal process/ procedure assessment, helping in product control and service quality improvement. Some of the key concerns cited by these interviewees include lack of top management support for collaborating with suppliers, employees reluctant to spend time on knowledge sharing, fear of hosting 'knowledge practices' and low awareness and realisation of the value and benefit of knowledge possessed by others.

\subsection{Managing change associated with sustainable procurement initiatives}

Senge et al. (2004) noted that, in business, the word 'change' means several often contradictory things. Sometimes it refers to the external changes in technology, customers, competitors, market structure, or the social and political environment. Sometimes it also refers to internal changes such as practices, styles and strategies. The emergence of sustainable organisations, however, has been argued to be dependent upon the institutionalisation of sustainability beliefs and processes into the very fabric of modern organisations (Doppelt, 2009). This calls for a change in 
management philosophy, whereby organisational actions will need to go far beyond technical fixes and embrace responsible and sustainable development values, beliefs and behaviours. With mindful planning, however, there is a host of mechanisms and models that can be used to facilitate change processes. Through the postal survey questionnaires, respondents were asked to indicate the level of implementation of key change-management initiatives for dealing with sustainable procurement initiatives on a 4-point Likert scale ranging from 'Don't have any plan for implementation (1)', 'Planned to be implemented in the next 5 years (2)', 'Implemented but not in current use (3)' and 'Implemented and in use (4)'. Table 2 shows the level of implementation of key change-management initiatives for dealing with sustainable procurement initiatives as indicated by 53 respondents who participated in the postal survey questionnaire phase of this study. The data presented in Table 2 are only the response on key change-management initiatives that have been implemented and in use for dealing with sustainable procurement initiatives.

It is evident from Table 2 that a specific board member/director/ adviser/manager responsible for sustainable procurement initiatives $(53 \%)$ is the most implemented of the change-management initiatives. This is closely followed by a written sustainable procurement policy (45\%), a reward system to promote sustainable procurement initiatives $(38 \%)$, and formal training programmes related to sustainable procurement initiatives (26\%). Whittington et al. (1999) noted that the focus of change is not only on organisational process and structure but also on organisational culture. This will, in turn, help harness the discretionary effort essential for installing a sustainable enterprises culture and successfully propelling the entire organisation into the future. However, study results suggest that cultural change initiatives, such as reward systems for promoting sustainable procurement initiatives and training programmes related to sustainable procurement initiatives, are not quite institutionalised yet in the UK construction sector.

Change management initiatives Total number of respondents indicated $(N=53)$

Specific board member/director/ adviser/manager responsible for sustainable procurement initiatives

$28(53 \%)$

A written sustainable procurement policy

A reward system to promote sustainable procurement initiatives

Formal training programme(s) related to sustainable procurement initiatives

Table 2. The level of implementation of change management initiatives to deal with sustainable procurement initiatives
To validate the quantitative results and in order to explore these data further in depth, interviewees were asked through face-toface interviews to list and describe key change-management initiatives for dealing with sustainable procurement initiatives that have been implemented in their organisations. Analysis of the qualitative data is discussed below.

\subsubsection{A written sustainable procurement policy}

Of the interviewees, nine out of 17 noted that their organisations had implemented a written sustainable procurement policy. For example, a typical written sustainable procurement policy in one of the interviewed organisations includes

\footnotetext{
'Organisation " $\mathrm{x}$ " is committed to leading by example and promoting the use of environmentally sustainable and socially responsible goods and services. To support this goal, organisation " $\mathrm{x}$ " will formally integrate environmental and social considerations into procurement decisions and ensure that all procurement activities are consistent with this policy. Preference will be given to the purchase of environmentally sustainable and socially responsible goods and services whenever they perform satisfactorily and are available at a reasonable price. All business partners and suppliers must comply both with the principles laid out in this policy and the applicable laws in the countries in which they operate.'
}

The aforementioned sustainable procurement policy statement describes an organisation's commitment to social and environmental responsibility. The benefits or costs associated with sustainability initiatives depend on many factors, such as the sector of activity, distinctions between preventive and palliative actions, environmental objectives and firm capabilities, which can vary significantly from one case to another (Wagner et al., 2002). Most often cited areas covered in a written procurement policy include codes of conduct with suppliers (eight of the nine), supplier social responsibility issues (six of the nine), ethical trading (five of the nine) and supplier environmental commitment (nine of the nine).

\subsubsection{Creation of new positions and job roles to deal with sustainable procurement initiatives}

Of the interviewees, eight out of 17 noted that their organisations had created new positions and job roles to deal with sustainable procurement initiatives. It is evident from the above data that the creation of new positions and job roles for dealing with sustainable procurement initiatives is relatively very low among the construction organisations. Some specific new positions and job roles include 'sustainable procurement director', 'sustainable purchasing manager', 'ethical manager' and 'sustainable procurement champion'. From the above results, it is evident that there is a wide gap in the job market for the newly emerging area of sustainable procurement in the construction sector. Without appropriate organisational structure, organisations may not reap all the benefits associated with sustainability initiatives (Dunphy et al., 2007). Therefore, the alignment of strategy, structure and management systems are essential for organisations to both coordinate activities and motivate employees towards implementing sustainable procurement initiatives. 


\subsubsection{Reward systems to promote sustainable procurement initiatives}

Of the interviewees, seven out of 17 noted that their organisations had implemented reward systems to promote sustainable procurement initiatives. Experts such as Doppelt (2009), Dunphy et al. (2007) and Epstein et al. (2010) emphasised that reward systems are a critical tool to implement sustainability initiatives. This is because they align with the interests of senior managers, all employees, and suppliers. However, in this study, the level of implementation of reward systems to promote sustainability initiatives is relatively low. For example, one of the interviewees stated that

\footnotetext{
'We evaluate our suppliers on 25 measures to determine how well they adhere to sustainable practices. Suppliers accepted into the programme are awarded points for meeting environmental, social, and economic criteria; the more points they earn the more business we did. Preferred suppliers will typically receive a $5 \%$ premium on each pound of material they supply to us. They can also win long-term contracts to reduce market risk and receive credit to fund improvements that promote sustainability.'
}

The aforementioned view of the interviewee clearly suggests that organisations are rewarding their suppliers in terms of cash awards, increased purchase volumes, preferred supplier status, buyers' direct investment in suppliers' operations and training suppliers' personnel.

\subsubsection{Formal training programmes related to sustainable procurement initiatives}

Comprehensive executive training programmes are valuable ways to raise awareness and nurture buy-in from managers responsible for implementing sustainability-oriented change initiatives (Kotter, 1996; Senge et al., 2007). In this study, five out of 17 interviewees noted that their organisations had implemented formal training programmes related to sustainable procurement initiatives. Typical topics covered under formal training programmes related to sustainable procurement include green purchasing, awareness of environmental and social sustainability issues, environmental and social standards, training on sustainable procurement policies, labour standards, sustainable procurement and business benefits and training on sustainable procurement-related tools and case studies.

It was suggested that sustainability is not a stand-alone issue but a dimension of management culture (Holliday et al., 2002; Savitz and Weber, 2006). As such, sustainability-related skills will have to reach further than personal relations skills. Hence, across the construction sector, sustainable procurement-related themes should be gradually integrated into management training and functional departments across all levels of the organisation including strategy, design, procurement, marketing, logistics, sales, human resources, communication and operations.

\section{Conclusion}

The ongoing sustainability movement requires organisations to extend their focus beyond traditional economic objectives to a triple bottom line approach that simultaneously accounts for economic, ecological and social performance. However, how to manage the paradox of improving social, environmental and financial goals simultaneously is one of a company's biggest challenges. The research reported in this paper found that survey respondents and interviewees appear to be well informed about sustainable procurement and its implementation is gaining traction. The initiatives implemented under the umbrella of sustainable procurement are very diverse; however, four major initiatives need to be noted: (1) integrating environmental and social criteria into the supplier selection process, (2) monitoring supplier environmental and social performance, (3) ethical trading and (4) collaborating with suppliers. For sustainable procurement, a key factor is the management of inter-organisational relationships. This requires supplier-engagement strategies, moving from policing and compliance activities to developmental and collaborative activities with suppliers. In this study, most of the organisations were from the private sector where sustainable procurement strategies were implemented to reduce operating costs, protect or enhance reputation, or the result of stakeholder pressure, government regulation/legislation or top management commitment.

Prior research suggests that this is a widespread problem across many industries and is not confined to the UK construction sector alone. Research finding have identified that integrating sustainable procurement initiatives into existing business models can often be a complex process. Therefore, it is recommended that there is an urgent need to explore the challenges and issues associated with the integration of sustainable procurement initiatives into existing business models. It is worthwhile to consider a holistic view of sustainable procurement (i.e. simultaneous consideration of the environmental, social and economic sustainability dimension) rather than viewing it in isolation.

Taken together, the impact of management commitment and leadership, sustainability-related policies, structures, reward systems, training programmes and performance reporting are key factors in successful implementation of sustainable procurement initiatives. Furthermore, the scarcity of knowledge and expertise associated with sustainable procurement initiatives is, and will continue to be, a huge challenge for many construction organisations. Therefore, training programmes related to the management of knowledge associated with sustainable procurement initiatives will help leaders, managers and change agents to understand better how to craft and implement various sustainability-related strategies for competitive advantage. This paper provides a richer insight into the understanding and awareness of the meaning of sustainable procurement initiatives at a conceptual level.

Given that the research reported in this paper is largely exploratory in nature, the results presented here provide a useful insight for the purposes of generalisability and repeatability. Therefore, it is recommended that additional research should explore the complex issues associated with implementing sustainable procurement initiatives within and across the various business models available. 
The nuances, which should focus on capturing the critical tensions and drivers, particularly the socio-cultural paradigms that can often influence knowledge embeddedness within organisational settings, are also worthy of investigation. Furthermore, this study does not report the differences between the approaches of micro enterprises, small and medium-sized enterprises and large organisations to sustainable procurement initiatives for improved competitiveness.

\section{REFERENCES}

Accenture (2013) The UN Global Compact-Accenture CEO Study on Sustainability 2013. Accenture Consulting, New York, NY, USA.

AccountAbility (2004) Gradient: Promoting Best-Practice Management of Supply Chain Labour Standards. AccountAbility, London, UK.

Barraket J and Weissman J (2009) Social Procurement and its Implications for Social Enterprise: A Literature Review, The Australian Centre for Philanthropy and Nonprofit Studies, Queensland University of Technology, Brisbane, Australia, Working Paper No. CPNS 48. See http://eprints.qut.edu.au/ 29060/1/Barraket_and_Weissmann_2009_Working_Paper_ No_48_Final.pdf (accessed 10/11/2014).

Baruch Y and Holtom BC (2008) Survey response rate levels and trends in organizational research. Human Relations 61(8): 1139-1160.

Beer M and Nohria N (2000) Cracking the change of code. Harvard Business Review 78(3): 133-141.

Benn S, Dunphy D and Griffiths A (2014) Organisational Change for Corporate Sustainability. Routledge, London, UK.

Bryman A and Bell E (2007) Business Research Methods. Oxford University Press, London, UK.

Carbon Trust (2013) Make Business Sense of Scope 3. Carbon Trust, London, UK.

Creswell JW (2009) Research Design: Qualitative, Quantitative and Mixed Methods Approaches. Sage, Thousand Oaks, CA, USA.

Doppelt B (2009) Leading Change Toward Sustainability: A Change-Management Guide for Business, Government and Civil Society. Greenleaf Publishing, Sheffield, UK.

Dunphy D, Griffiths A and Benn S (2007) Organisational Change for Corporate Sustainability. Routledge, London, UK.

Elkington J (2001) The Chrysalis Economy: How Citizen CEOs and Corporations Can Fuse Values and Value Creation. Capstone Publishing, Oxford, UK.

Epstein MJ, Buhovac AR and Yuthas K (2010) Implementing sustainability: the role of leadership and organisational culture. Strategic Finance 91(10): 41-47.

EU (European Union) (2011) Buying Green! A Handbook on Green Public Procurement. Publications Office of the European Union, Luxembourg.

Fellows R and Liu A (2014) Research Methods for Construction. Wiley Blackwell, Oxford, UK.

Fombrun CJ and Shanley M (1990) What's in a name? Reputation building and corporate strategy. Academy of Management Journal 33(2): 233-258.
Handfield R, Melnyk S, Calantone R and Curcovic S (2001) Integrating environmental concerns into the design process: the difference between theory and practice. IEEE Transactions on Engineering Management 48(2): 189-208.

Hawkins E (2006) Corporate Social Responsibility: Balancing Tomorrow's Sustainability and Today's Profitability. Palgrave Macmillan, Basingstoke, UK.

HM Government (2009) Low Carbon Construction Innovation and Growth. HM Government, London, UK.

Holliday C, Schmidheiny S and Watts P (2002) Walking the Talk: The Business Case For Sustainable Development. Greenleaf Publishing, Sheffield, UK.

Hollos D, Blome C and Foerstl K (2012) Does sustainable supplier co-operation affect performance? Examining implications for the triple bottom line. International Journal of Production Research 50(11): 2968-2986.

ISO (International Standardization Organization) (2015) ISO 14001: Environmental Management. ISO, Geneva, Switzerland.

Kahlenborn W, Moser C, Frijdal J and Essing M (2011) Strategic Use of Public Procurement in Europe - Final Report to the European Commission. Adelphi, Berlin, Germany, MARKT/ 2010/02/C

Koplin J, Seuring S and Mesterharm M (2007) Incorporating sustainability into supply policies and supply processes in the automotive industry - the case of Volkswagen. Journal of Cleaner Production 15(11): 1053-1062.

Kotler P and Lee N (2005) Corporate Social Responsibility: Doing the Most Good for Your Company and Your Cause. Wiley, Hoboken, NJ, USA.

Kotter J (1990) A Force for Change: How Leadership Differs from Management. Simon and Schuster, New York, NY, USA.

Kotter J (1996) Leading Change. Harvard Business School, Boston, MA, USA.

KPMG (2013) Survey of Corporate Responsibility Reporting. KPMG International Cooperative, London, UK.

Liamputtong P and Ezzy D (2005) Qualitative Research Methods. Oxford University Press, South Melbourne, Australia.

McCrudden C (2004) Using public procurement to achieve social outcomes. Natural Resources Forum 28(4): 257-267.

Meehan J and Bryde DJ (2011) Sustainable procurement practice. Business Strategy and the Environment 20(2): 94-106.

Min H and Galle WP (2001) Green purchasing practices of US firms. International Journal of Operations and Production Management 21(9/10): 1222-1238.

Porter ME (1985) Technology and competitive advantage. Journal of Business Strategy 5(3): 60-78.

Porter ME and Kramer M (2011) Creating shared value. Harvard Business Review 89(1): 62-77.

Porter ME and van der Linde C (1995) Green and competitive: ending the stalemate. Harvard Business Review 73(5): 120-134.

PricewaterhouseCoopers (2009) Collection of Statistical Information on Green Public Procurement in the EU - Report on Data Collection Results. PricewaterhouseCoopers, Amsterdam, Netherlands. 
Renda A, Pelkmans J, Egenhofer C et al. (2012) The Uptake of Green Public Procurement in the EU27. Centre for European Policy Studies and College of Europe, Brussels, Belgium.

Renukappa SH (2009) A Theoretical Framework for Managing Change and Knowledge Associated with Sustainability Initiatives for Improved Competitiveness. $\mathrm{PhD}$ Thesis, Glasgow Caledonian University, Glasgow, UK.

Rwelamila PD, Talukhaba AA and Ngowi AB (2000) Project procurement systems in the attainment of sustainable construction. Sustainable Development 8(1): 39-50.

Savitz AW and Weber K (2006) The Triple Bottom Line. Jossey-Bass, San Francisco, CA, USA.

Senge PM, Scharmer CO, Jaworski J and Flowers BS (2004) Presence: An Exploration of Profound Change in People, Organizations and Society. Random House, New York, NY, USA.

Senge PM, Lichtenstein BB, Kaeufer K, Bradbury H and Carroll JS (2007) Collaborating for systemic change. MIT Sloan Management Review 48(2): 44-53.

Silverman D (2004) Qualitative Research: Theory, Method and Practice. Sage, Thousand Oaks, CA, USA.

Teddlie C and Tashakkori A (2003) Major issues and controversies in the use of mixed methods in the social and behavioural sciences. In Handbook of Mixed Methods in Social and Behavioural Research (Tashakkori A and Teddlie C (eds)). Sage, Thousand Oaks, CA, USA, pp. 3-50.

UN Global Compact (2013) Corporate Sustainability in the World Economy. UN Global Compact Office, New York, NY, USA. UNDP (United Nations Development Program) (2008) Environmental Procurement Practice Guide, United Nations
Development Program Practice Series. Procurement Support Office, UNDP, Copenhagen, Denmark.

van Kleef JAG and Roome NJ (2007) Development capabilities and competence for sustainable business management as innovation: a research agenda. Journal of Cleaner Production 15(1): $38-51$.

Varnäs A, Balfors B and Faith-Ell C (2009) Environmental consideration in procurement of construction contracts: current practice, problems and opportunities in green procurement in the Swedish construction industry. Journal of Cleaner Production 17(13): 1214-1222.

Wagner M, Van Phu N, Azomahou T and Wehrmeyer W (2002) The relationship between the environmental and economic performance of firms: an empirical analysis of the European paper industry. Corporate Social Responsibility and Environmental Management 9(3): 133-146.

Welford R (1997) Hijacking Environmentalism: Corporate Responses to Sustainable Development. Earthscan Publications, London, UK.

Whittington R, Pettigrew A, Peck S, Fenton E and Conyon M (1999) Change and complementarities in the new competitive landscape: a European panel study. Organization Science 10(5): 583-600.

Williams RJ and Barrett JD (2000) Corporate philanthropy, criminal activity, and firm reputation: Is there a link? Journal of Business Ethics 26(4): 341-350.

Yuan F and Woodman RW (2010) Innovative behavior in the workplace: the role of performance and image outcome expectations. Academy of Management Journal 53(2): 323-342. 